\title{
Beyond the 'two cultures' in the teaching of disaster: or how disaster education and science education could benefit each other
}

\author{
Wonyong Park \\ University of Oxford, Oxford, UK
}

\begin{abstract}
This is a post-peer-review, pre-copyedit version of an article published in Educational Philosophy and Theory. The final authenticated version is available online at https://doi.org/10.1080/00131857.2020.1751126
\end{abstract}

\begin{abstract}
Looking at the current discourse on how to teach disaster, one apparent gap is that the scientific aspect of disaster is discussed and taught mostly in isolation from its human aspect. Disaster educators seem to be primarily interested in addressing issues such as social vulnerability, community resilience, personal action-related knowledge and emotion rather than the scientific basis of disasters, whereas science educators rarely make connections between the scientific accounts of disasters and the social and political contexts that surround them. In this theoretical paper, I claim that this disconnect is problematic and that overcoming it is a key to understanding and teaching disaster in a more nuanced and comprehensive manner. Drawing primarily on science and technology studies (STS) on disaster, I explore the potential of interpreting disasters as 'failures' of socio-technical systems, which helps us unearth the inner workings of the complex network of science, technology and society in the wake of calamities. STS challenges the dichotomous understanding of the material and social worlds and takes a view that they coconstruct each other to constitute socio-technical systems. Taking such an approach to disaster allows a synthetic understanding of the natural, technological and human-made disasters that we are faced with in the age of uncertainty and complexity. Based on the ideas of STS and examples of recent disasters in East Asian countries, I argue that disaster education and science education can cross-pollinate in tackling the post-disaster hardship and cultivating responsible citizens.
\end{abstract}

Keywords: disaster education, science education, science and technology studies, interdisciplinarity, system accident, actor-network theory 


\section{The two cultures in how we study and teach disaster}

Science and disasters have had a long, chequered and complicated relationship throughout human history. In most pre-modern societies across the East and West, natural disasters such as droughts, floods, typhoons and earthquakes, were thought to be ruled by divine providence. As a result, disasters were frequently ascribed to God's wrath and wilful chastisement for human sins (Israel, 2011). Science, on the contrary, was deemed to be the essence of human intellect, providing rational expectations about the future. As Knowles (2014) put it, science represented 'the beauty and rationality of the planned', whereas disaster was rather considered 'a realm of random accident and distress' (p. 131). The modern idea of disasters as natural phenomena to be studied scientifically was provoked by the Great Lisbon Earthquake of 1755, which posed a serious challenge to the dichotomous understanding of science and disaster (Dynes, 2000; see Figure 1). The catastrophic magnitude 9.0 (estimated) earthquake, which struck and then devastated Lisbon on the All Saint's Day while people were lighting candles and praying in churches, invoked a vigorous debate on the cause of earthquakes that was fuelled by the wider movement toward secularisation in eighteenth century Europe (Israel, 2011; Merchant, 2016). ${ }^{1}$

As we entered a modern industrial society, new types of disasters emerged that required yet another significant change in the understanding of the relationship between disaster and science. Technological disasters, such as the collapses of buildings and bridges, explosions of chemical and nuclear plants, and aircraft accidents, have become more frequent and problematic than natural disasters were in pre-modern societies. One notable point here is that science and technology is arising fast both as a major source of disasters, not only being an instrument to control and cope with them as it was in the past. Leading theorists in risk society have contended that the success of contemporary science and technology is paradoxically producing 'manufactured uncertainty' (Giddens, 1995, p. 78). Major technological disasters over the past three and a half decades, such as the Chernobyl disaster (1986), the BP Deepwater Horizon oil spill (2010), the NASA Space Shuttle Challenger disaster (1986) and the Bhopal gas tragedy (1984) have provided abundant evidence that science and technology are inseparable from disasters and also are essential to understanding them. These human-made disasters are particularly significant in East and

\footnotetext{
${ }^{1}$ Often considered 'the first modern disaster' (Dynes, 2000), the Lisbon Earthquake had an important philosophical ramification by prompting the transition in the conception of disasters as physical phenomena rather than solely divine intervention. In addition, it gave rise to several Enlightenment thinkers' critical reflection on the nature of disaster, shattering the widely held belief that God created 'the best of all possible worlds' (Leibniz, 1710/1985). Perhaps the most famous example is Voltaire, who ridiculed in his satire Candide such apparent paradox between the killing of innocent people and the idea of God's providence. For a fuller account of the impact of the Lisbon Earthquake on the Enlightenment thoughts regarding nature, God and disaster, see Israel (2011).
} 
Southeast Asian countries, where the rapid growths of economies and their reliance on technological advances have interacted with the vulnerability and resilience of society (Kim \& Sohn, 2018). For example, the white paper on the cause of the humidifier disinfectant disaster that swept Korea starting in 2011 pointed out that excessive trust in modern science and technology among Koreans was one contributing factor to the unprecedented disaster (LIIC, 2014). In addition to the changing role of technology in today's disasters, another complicating factor is that it is often not so obvious whether a disaster is natural or human-made. This is because some technological disasters are in fact caused by natural disasters (as in the 2011 Fukushima Daiichi nuclear disaster caused by the Great East Japan Earthquake), while some natural disasters are induced by human activities (as in the 2017 Pohang earthquake in Korea, which was possibly triggered by geothermal energy production activities; Grigoli et al., 2018; see Coeckelbergh, 2016 for a fuller discussion on the entanglement between natural and human aspects of natural hazards).

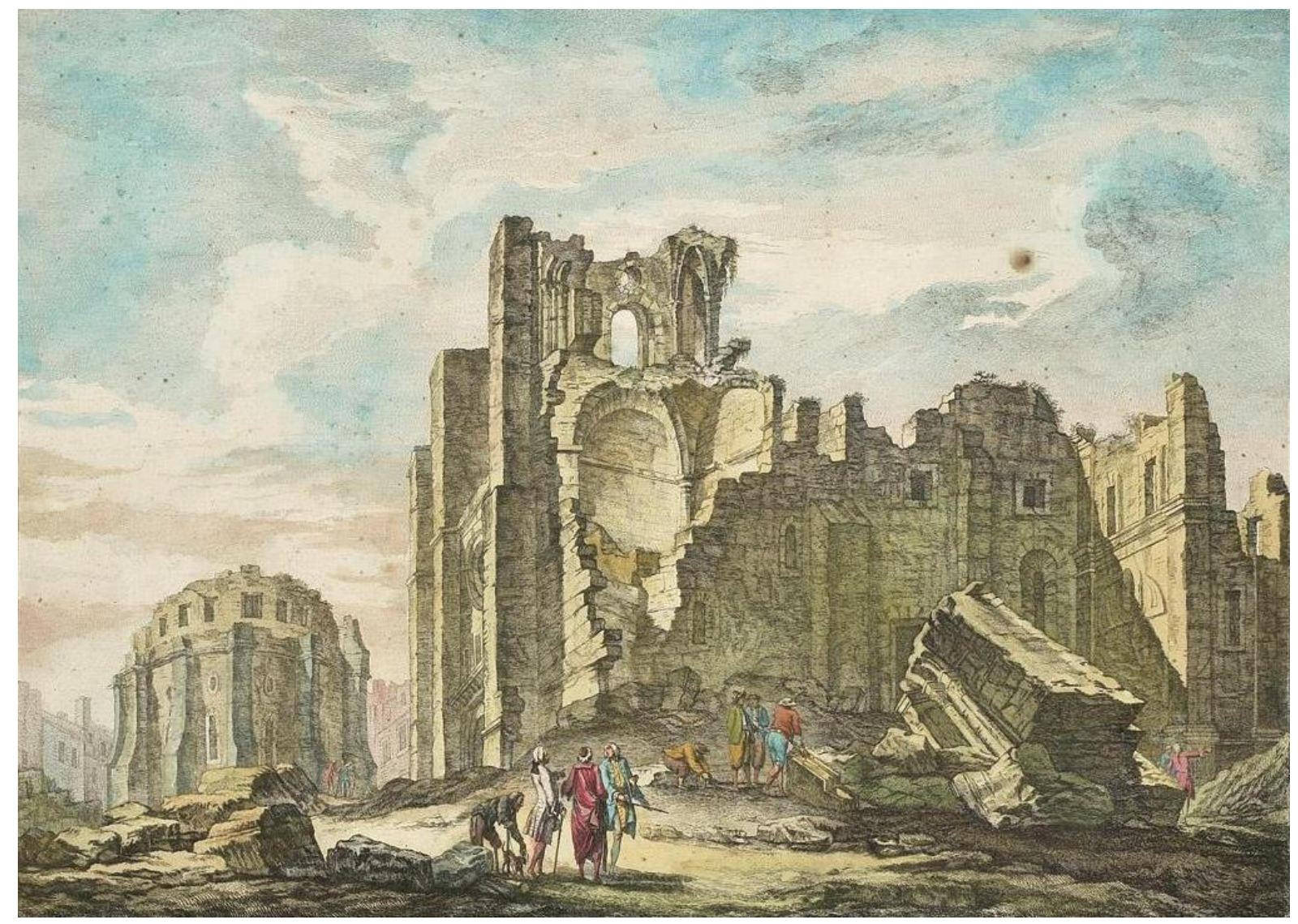

Figure 1. A wood engraving (made 1757-1760) depicting the ruins of the Lisbon Cathedral after the Great Earthquake of 1755. This colossal earthquake and subsequent tsunami destroyed the city and claimed 30,000 to 60,000 lives in Lisbon alone. (Original work by Jacques-Philippe Le Bas [1707-1783]; Public domain image retrieved 21 December 2019 from 
https://commons.wikimedia.org/wiki/File:Ruinas_da_S\%C3\%A9_de_Lisboa_ap\%C3\%B3s_o_Terramot o_de_1755_-_Jacques_Philippe_Le_Bas,_1757.png)

Despite the centrality of science and technology in understanding disasters in the modern world, the scientific aspects of disaster seem rather divorced from its social aspects when it comes to how disasters are taught in schools. It is well acknowledged that proper understanding of disasters requires knowledge of both their geophysical, meteorological and technical mechanisms and their social, economic and political contexts related to societal vulnerability (Hewitt, 1997). Whereas disaster is a genuinely interdisciplinary topic studied in geology, meteorology, oceanography, sociology, psychology and anthropology, among others, the majority of existing disaster education programmes focus mainly on the human and social aspects of disasters, such as issues of social vulnerability, community resilience, and personal action-related knowledge, emotion and so forth (Johnson, Ronan, Johnston \& Peace, 2014). Turning to the science curricula, most of them put emphasis on how earthquakes and hurricanes are generated from natural conditions and how their magnitude and impact are measured and calculated, but remain silent of how such natural disasters relate to the community and global society. In other words, the human and social aspects of disasters are taught separately from their scientific and technological aspects with no connections being made between the two. What seems even more problematic is that most anthropogenic technological disasters, which are becoming increasingly common and reflect the high degree of interaction between science and society, are rarely represented in the curriculum -. In a sense, the way in which disaster is portrayed in today's formal education is strikingly reminiscent of the 'two cultures' that divided the 'intellectual life of the whole of western society', as famously lamented by C. P. Snow $(1959$, p. 3) some 60 years ago. One of the vexing consequences of this divide is the public's scepticism toward science. The value-free and neutral image of science as being isolated from society, when challenged by nuclear reactor meltdowns and environmental disasters, makes the public question their trust in the expertise of scientists and the authority of science (Fortun \& Frickel, 2013). I will come back to this issue later in this article.

Notwithstanding its growing academic and practical importance, there seems to remain some ambiguities concerning the scope of disaster education-who are responsible for it, what kinds of activities it entails, and what aims it should pursue-which need some clarification before I develop my argument about it. Throughout this paper, I shall use 'disaster education' and 'science education' to broadly mean the fields of inquiry and practice, each featuring disaster literacy and scientific literacy (as will be described later) as its primary aim; In other words, I define the terms with respect to their disciplinary aims rather than their corresponding school subjects. This allows us to evade the potential asymmetry arising between the two terms when defined in the latter way (Consider that science is a well-established school subject, whereas the status of disaster in the 
curriculum is far less obvious). According to this aim-based characterisation, disaster education is something that can be pursued and practised in various school subjects including history, moral education, religious education, social studies, literature, science and technology, insofar as they contribute to promoting students' disaster literacy. In a similar vein, such characterisation implies that science education can address a wide range of natural/social objects and phenomena including disasters, where the acquisition of scientific literacy can help us understand and respond to them better. These broad definitions are highly suggestive of the cross-pollination between the two fields, leading to my key question: In what ways can the study of disaster enrich our understanding of/about science, and vice versa? My main upshot is to conceptualise a reciprocal relationship between disaster education and science education by delineating and exemplifying how the aims of each discipline could serve the other.

To do this, I build on the perspective of STS, which is an interdisciplinary academic field for investigating the interrelationship between science, technology and society. At the heart of STS is the recognition of the inseparability of science and technology from social structures and practices. STS sees scientific facts and technological artefacts as nothing but temporarily stabilised, heterogeneous networks of human and non-human actors entangled in the wider social and political relations. In this way, science and society do not exist separately but co-construct each other through the social processes of inscription, punctualisation, translation and registration (Latour, 1987). By interpreting social phenomena in terms of the interactions among actors and networks, STS is well suited for tracing and unearthing complex socio-technical events such as disasters and thus has the potential to give insights to better understand not only science and technology but also society (Law, 1991). To discuss the implications of the STS approach for teaching disaster, this paper is structured in the following way. In Section 2, I give an account of what it means to approach disasters from the STS perspective drawing particularly on the works of Bruno Latour and Charles Perrow. In Section 3, I propose a model that represents the potential reciprocity between disaster education and science education and demonstrate how this integration can benefit both fields. In Section 4, I explore several potential modes of integration and collaboration between the two fields based on the STS perspective and discuss some ramifications for initiating and supporting such efforts.

\section{Approaching disaster as a failure of socio-technical system}

STS is rooted in the philosophy of technology that started to flourish in the early twentieth century. Influential continental philosophers including Max Weber, Martin Heidegger, Hannah Arendt, Hans Jonas, Jacques Ellul and Günther Anders noted that technology is definitive of modern human lives, in the same way that religion defined the middle age and nature did the ancient Greece (Dusek, 2006). Their reflections on the place of technology in human life were largely 
motivated by such historical events of the century as the launch of Sputnik and the atomic bombings in Hiroshima and Nagasaki. In these early discussions, philosophers focused on criticising the dangers that it brings about to humans and societies, while taking the phenomenon of technology for granted, or as a 'black box' (Frassen, Lokhorst, \& van de Poel, 2018). A shift from this tradition came about in the 1980s, when the 'empirical turn' in the philosophy of technology began to emerge (Kroes \& Meijers, 2001). Bringing together contributions from various fields of social science as well as history and philosophy of science, STS has since accomplished an extraordinary success in explaining technological practice, providing an authentic and practicebased understanding of technological artefacts, knowledge and practice. Methodologically, STS scholars deviated from classical philosophers of technology by focusing on empirical investigation of how science and technology are constructed. Their attention was directed to the dynamic ways in which modern technology manifests itself while interacting with society. In his work Pandora's Hope: Essays on the Reality of Science Studies, Bruno Latour noted that:

When a machine runs efficiently, when a matter of fact is settled, one need focus only on its inputs and outputs and not on its internal complexity. Thus, paradoxically, the more science and technology succeed, the more opaque and obscure they become. (Latour, 1999, p. 304)

As represented in this quote, STS scholars claim that, as science and technology become successful, the human and non-human actors and their relationships that comprise the socio-technical system become invisible. ${ }^{2}$ Latour famously argued that once a system becomes stable, things get 'blackboxed' and their internal structure and mechanisms become invisible (Latour, 1987). When technical objects such as nuclear power plants, aircrafts, ships, water supply systems and urban transportation systems are functioning normally, we benefit from them without really realising what is inside them. It is only when things fail to work, or the network that holds humans and non-humans together collapses, that we become interested in these internal structure and mechanisms of the system. In this view, disasters can be critical events that unveil the hidden actors and networks that comprise the socio-technical system. Irwin (2019) made a similar

\footnotetext{
${ }^{2}$ The acronym STS can refer to 'science and technology studies' or 'science, technology and society'. Sismondo (2010) notes that these two meanings of STS were initially used to represent different fields, the former concerning a philosophically radical approach to scientific and technological practice and the latter focusing on the social issues related to scientific and technological advances. However, the two STSs have become gradually blended as researchers expanded their interest, making them gradually indistinguishable (Sismondo, 2010). In science education literature, STS is mostly used in the latter sense, particularly referring to a pedagogical approach that emphasises the interaction between science, technology and society (Vesterinen, Manassero-Mas, \& Vázquez-Alonso, 2014). Since the mid-2010s, the discussion on STS in science education has largely been absorbed into the broader discourse of 'socio-scientific issues' (SSIs) (Zeidler et al., 2005), which appears much more often in the recent literature. In this essay, I use STS to mean science and technology studies as an academic discipline, which helps us interpret disasters as socio-technical events, to draw educational implications.
} 
observation by stating that "we only really consider the way in which we occupy our environment when our attention is directed to the "faults" in the system' (p. 1). Understood this way, disasters, or the failures of systems, can be events that direct our attention to aspects of a socio-technical system that were previously unrecognised. This approach allows investigating the failures of socio-technical systems in the wider contexts of organisational culture, management systems, and the systems of beliefs and ethics in which technology is developed and operated.

Perrow's (1984/1999) pioneering work Normal Accidents: Living with High Risk Technologies marked a milestone in the study of disaster, paving ways to the STS approach to disaster. From an in-depth case analysis of the Three Mile Island (TMI) nuclear accident in Pennsylvania, United States, in 1979, Perrow claimed that many technological disasters are indeed 'system accidents' (or 'normal accidents'), which occur in complex and tightly coupled technological systems such as nuclear power plants, chemical plants, airways and marine transport (Perrow, 1984/1999). These are easily found around us today and involve interactions of two or more failures that cannot be anticipated or comprehensible even to the trained engineers (Perrow, 1984/1999). There is an understandable tendency that people find the cause of the accidents in the employees who operated the failed system (Evan \& Manion, 2002), as in the TMI accident where the official explanation was an operational mistake by a staff member. However, STS scholars note that these kinds of accounts for the causes of disasters are more often a post facto reconstruction of the event (Pinch, 2012) that undermines the failures of design and of organisational and socio-cultural systems. Perrow indicated that the more fundamental but hidden causes of the TMI accident were the complex interactions and tightly coupled systems entrenched in the nuclear power plant.

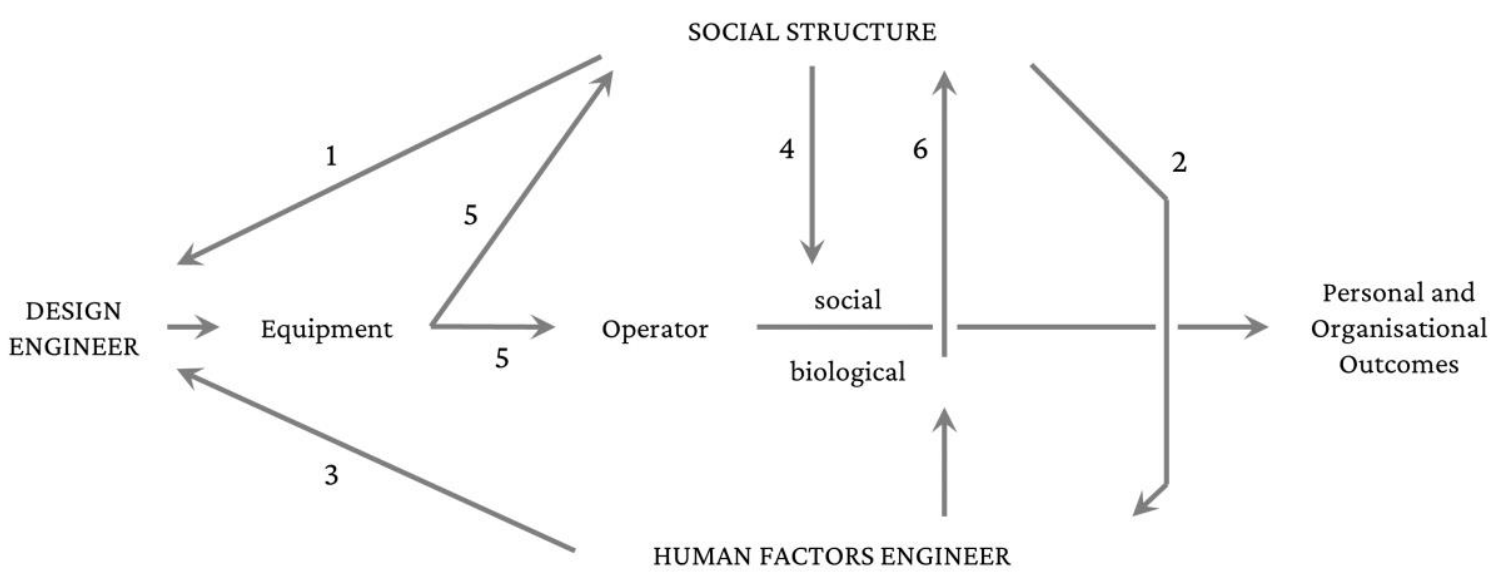

Figure 2. The context of design (from Perrow, 1983). Perrow emphasised that in a complex system where a disaster occurs, the interrelationships among engineers, equipment, operators, social structure and human factors have a crucial role in understanding the success and failure of the system. 
The STS approach to disaster as outlined thus far provides a useful lens through which educators can dissolve the border between the two cultures and seek integration (see Table 1), on several grounds. First, this approach acknowledges the interdependence of nature, science and human action in the event of a disaster, an aspect that has been increasingly emphasised by disaster education researchers (Fien, 1993; Nielson \& Lidstone, 1998). In particular, by granting humans and non-human actors equal amounts of agency, STS avoids simply attributing the cause of a disaster to any specific individual, which allows a more comprehensive understanding that takes into consideration the uncertainty and complexity of modern technology and science-technologysociety interactions. Second, they allow understanding of natural and anthropogenic disasters in a coherent manner; After all, both are essentially the same 'system failures' in the view of STS, no matter what actors and networks the system consists of. These characteristics of the STS perspective make it well suited for illuminating the socio-technical mechanisms that are intertwined in the wake of natural and technological disasters and enable educators to translate them so they can be used in school curricula. They also help us explore the potential crosspollination of disaster education and science education in dealing with disaster, by giving clues about how each field could serve the aims of the other.

Table 1

The scientific, humanistic and integrative approaches to disaster education

\begin{tabular}{|c|c|c|c|}
\hline & Scientific approach & Humanistic approach & Integrative approach \\
\hline $\begin{array}{l}\text { Nature of } \\
\text { disaster }\end{array}$ & $\begin{array}{l}\text { Natural and technological } \\
\text { events; something } \\
\text { predictable }\end{array}$ & $\begin{array}{l}\text { Social problems; something } \\
\text { to be overcome }\end{array}$ & $\begin{array}{l}\text { Failures of socio-technical } \\
\text { systems }\end{array}$ \\
\hline $\begin{array}{l}\text { Cause of } \\
\text { disasters }\end{array}$ & $\begin{array}{l}\text { Natural hazards, physical } \\
\text { agents }\end{array}$ & $\begin{array}{l}\text { Human vulnerability, } \\
\text { weakness in social } \\
\text { structures or systems }\end{array}$ & $\begin{array}{l}\text { Complexity and uncertainty } \\
\text { inherent in the system }\end{array}$ \\
\hline $\begin{array}{l}\text { Result of } \\
\text { disasters }\end{array}$ & Physical destruction & Social damage & $\begin{array}{l}\text { Physical destruction and } \\
\text { social damage }\end{array}$ \\
\hline $\begin{array}{l}\text { Purpose of } \\
\text { disaster } \\
\text { education }\end{array}$ & $\begin{array}{l}\text { Understanding the } \\
\text { physical mechanisms of } \\
\text { disaster, preventing } \\
\text { injuries and deaths }\end{array}$ & $\begin{array}{l}\text { Developing disaster- } \\
\text { resilient individuals and } \\
\text { communities }\end{array}$ & $\begin{array}{l}\text { Understanding the nature } \\
\text { of science, making } \\
\text { scientifically informed } \\
\text { decisions with regard to } \\
\text { disasters, engaging in } \\
\text { disaster-related socio- } \\
\text { scientific issues. }\end{array}$ \\
\hline
\end{tabular}

In recent years, STS researchers have started to direct their attention to natural and technological disasters in society. The 9/11 terror, Hurricane Katrina, the Deepwater Horizon oil spill, the Great 
East Japan Earthquake and subsequent Fukushima Daiichi Nuclear Power Plant accident have prompted STS scholars to investigate the complicated interaction of nature and society, hazards and vulnerability, and natural sciences and social sciences that are at play in the event of a disaster (Hindmarsh, 2013). In a recent review of the STS research on disasters, Fortun et al. (2014) provided an STS-based definition of disasters as 'failures of diverse, nested systems, producing injurious outcomes that cannot be straightforwardly confined in time or space, nor adequately addressed with standard operating procedures and established modes of thought' (p. 1004). STS scholars Dowty and Allen (2011) contended that taking the STS perspective contributes to understanding how citizens who are non-experts can participate in socio-technical issues in various ways. At the same time, STS disaster researchers have been examining how science and technology produce risk in modern society while simultaneously providing tools to mitigate and cope with it (Fortun et al., 2014).

It is also noteworthy that STS researchers have recently been actively engaged in the application of their research work to public understanding of science and disaster. The Teach 3.11 website (https://teach311.org) was established by scholars in the history of science and technology in response to the Fukushima disaster and has been archiving and compiling resources related to the disaster and turning them into teaching materials (Onaga, 2011). STS scholar Sulfikar Amir at Nanyang Technological University, Singapore, directed an educational documentary film entitled Healing Fukushima in 2016 with his colleagues that offered an in-depth portrayal of the local physicians' effort in dealing with the radiation hazard and public health in the post-disaster community, as well as how a new mode of knowledge production emerged in the wake of the unforeseen calamity (Fischer, 2019). In Korea, STS researchers based at the Korea Advanced Institute of Science and Technology (KAIST) built a platform called Teach Sewol (http://teachsewol.org) to 'engage with the larger academic community and the public in analysing and debating a series of recent disasters in South Korea' (Lee \& Jeon, 2015, para. 1), as a response to the tragic 2014 sinking of the Sewol Ferry that claimed 304 lives, most of whom were high school students and teachers on the way to a field trip. These initiatives support the view that STS has significant potential to link science and society in the teaching of disaster, both theoretically and practically.

\section{Proposing a reciprocal relationship of science education and disaster education}

Approaching disaster through the lens of STS allows a critical and nuanced appraisal of the relationship between science, technology and society. It provides a useful lens for exploring how the fields of disaster education and science education can benefit each other using two reciprocal concepts (Figure 3), namely disaster-related scientific literacy and science-related disaster literacy. 
Below I will illustrate each of these concepts by suggesting some potential contributions that the study of disaster can make in service of science education across grade levels, and vice versa.

Science-related disaster literacy: Understanding the scientific knowledge related to disasters to utilise it in responding to disaster events on a personal level, and engaging in the social debate on disasters based on scientific understanding

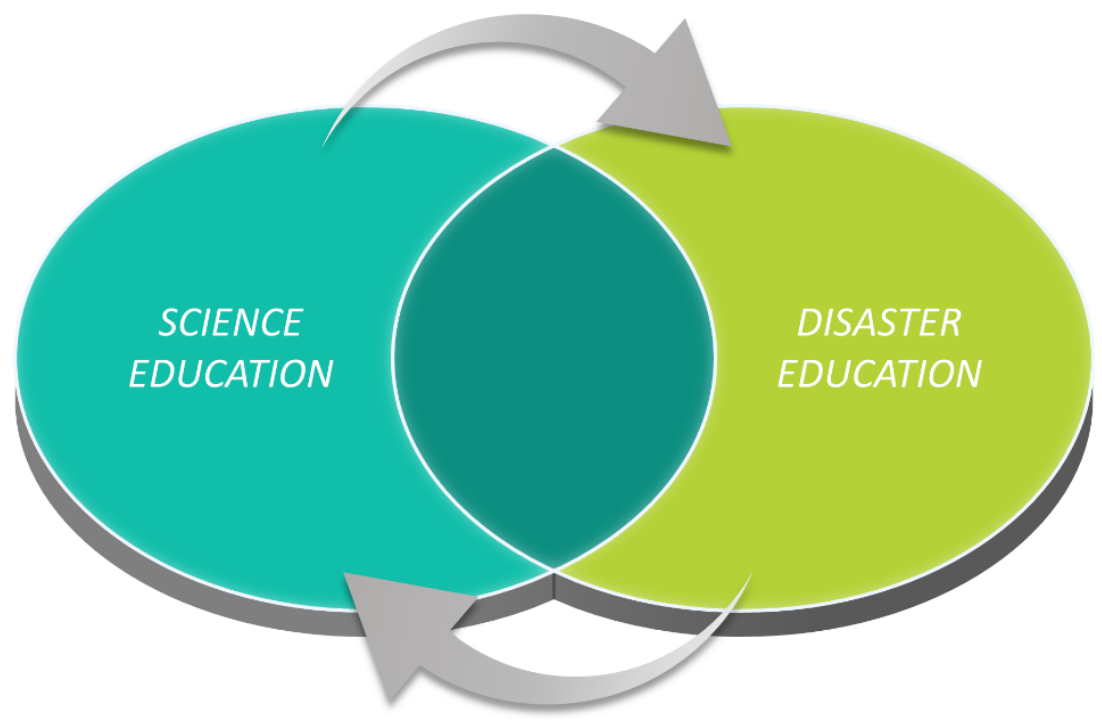

Disaster-related scientific literacy: Understanding the practices of science and technology in mitigating and responding to disasters, thereby understanding the aims and methods of science and its interaction with society

Figure 3. The reciprocal relationship between science education and disaster education

\subsection{Disaster-related scientific literacy}

There is a general agreement among science educators today that the aim of school science is to cultivate the scientific literacy of individuals, as represented in several key science curriculum documents (AAAS, 1989; NGSS Lead States, 2013). The OECD (2015) defined scientific literacy as 'the ability to engage with science-related issues, and with the ideas of science, as a reflective citizen' (p. 22). In the context of disasters in particular, this meaning of scientific literacy can be adapted as 'understanding the practice of science and technology in mitigating and responding to disasters, thereby understanding the aims and methods of science and its interaction with society'. In service of this aim, investigating disaster cases in science classrooms through the lens of STS can provide valuable opportunities to learn about how contemporary science operates within the context of wider society. Disasters also tell us how and why science can fail, the way science is reliant on and intertwined with technology and society and why scientific investigations of a disaster sometimes fail to produce an explanation that satisfies everyone. These issues regarding 
the nature of contemporary science and technology are arising fast as major agendas among philosophers of education (e.g., Peters, Rider, Hyvönen \& Besley, 2018) as well as science educators (e.g., Bencze \& Alsop, 2014; Sadler \& Zeidler, 2003), especially given the advent of post-normal science where 'facts are uncertain, values in dispute, stakes high and decisions urgent' (Funtowicz \& Ravetz, 1993, p. 744).

One useful example that illustrates the value of using disasters to promote scientific literacy by opening the black box was provided by science educators in Hong Kong in response to the Severe Acute Respiratory Syndrome (SARS) pandemic, which originated in China in 2002 and subsequently spread out to other countries across the Pacific such as Hong Kong, Taiwan, Singapore and Toronto, Canada. Lee (2008) and Wong, Kwan, Hodson and Yung (2009) claimed that the SARS disaster reveals important aspects of scientific literacy such as the role of science in understanding nature, constructing rational and convincing explanations and producing knowledge for technological application. They also found in the SARS-related scientific practices several important and generalisable features of contemporary science, such as interdisciplinary collaboration, intense competition and the crucial role of funding in scientific research. Sadler and Zeidler (2003) made a similar case with the misuse of dicholoro-diphenyl-trichloethane (DDT) during World War II and onward to control mosquitos, flies and agricultural pests, showing that its unpredicted and cascading interaction with the ecosystem and the lack of consideration about its environmental and health effects resulted in disastrous consequences.

Recent investigations on the Fukushima disaster have also unveiled diverse aspects of disasters that arise at the science-technology-society interface, which science curriculum makers should be aware of vis-à-vis disaster-related scientific literacy. First, STS research has profoundly shown that modern technologies such as the nuclear power plant are extremely complex, and even engineers do not have a full understanding of them because of the inherent uncertainties and contingencies underlying the socio-technical system (Fujigaki, 2015; Juraku, 2013). Science is no longer something that operates in a predictably linear fashion and can be clearly explained step by step, if indeed it ever was. This leads to the important conclusion that we need to admit the limits of science and teach about them, besides appreciating and underscoring its accomplishments. Science does not always succeed. Despite all the successes that humankind has achieved, we still cannot escape from failing. However, admitting the limits of science does not mean being pessimistic about it. In my view, school science tends to overlook the educational values of the failures and limits of science. It has focused on telling the story of how science has been, and will continue to be, successful in solving problems and bring safety, prosperity and longevity to us. This does not resemble how science works in the real world. Growing a blind faith in the omnipotence of science will result in losing trust when faced with failures such as disasters. Only by acknowledging its limits, can we keep our trust in science despite its recurring failures. 
Second, studies on the Fukushima disaster have revealed that the scientific knowledge and standards with regard to nuclear safety were not purely scientific but were also socially shaped, both pre- and post-disaster. In his analysis of the 'social shaping' of nuclear safety in Japanese society, Hara (2013) observed that it was the mobilisation of various actors, material entities, institutions and social structures by the pro-nuclear camp that created and maintained the preFukushima knowledge and belief about nuclear power safety in Japan. The social construction of 'safety' in Japan, he commented, 'could not control the capricious and enormous "disruptive power" of nature itself, which before the disaster was rather discounted as a background factor in the social shaping of nuclear power' (Hara, 2013, p. 36). The main lesson from this example is that what we know and believe about risk and safety are sometimes not so much scientific as they are social, and we should be critical of these 'socially approved' knowledge and beliefs. Another social dimension of scientific knowledge production was documented in Loh and Amir's (2019) study of the medical practitioners who struggled to discover proper medical knowledge in response to the unprecedented Fukushima disaster. The study found that the production of scientific knowledge related to radiation emergency medicine did not occur in a rigid and robust way, but rather was a contingent, flexible and piecemeal process that involved creating and modifying networks among medical experts in response to the developing crisis (Loh and Amir, 2019). The knowledge emerged in the process of blurring the boundaries of expertise and crossing the specialisation that was imposed by the institutionalisation of science (Loh and Amir, 2019).

Third, STS-based analyses of the Fukushima disaster have also illuminated some ways in which scientific and engineering practices are subject to cultural influence. This means that, contrary to the stereotypical 'universal' perception about science, there were some aspects that made the nuclear accident a 'made in Japan' disaster. Amir and Juraku (2014) point out that the Japanese nuclear engineers erroneously believed that they had more than enough technical knowledge to identify what went wrong and cope with the system malfunction, which resulted in inaccurate assessments of the accident during the first few weeks after it. Why did the engineers have such a strong overconfidence in the safety of the nuclear system? Amir and Juraku found that there was a prevalent notion of 'robustness' among the Japanese engineers that it is possible to build a technological system that can deal with destructive force. Such understanding of technology contributed to a culture of engineering in Japan that resulted in the failure of immediate reactions and prolongation of the crisis. The investigation commission's final report reiterated this point by stating that "we conclude that the accident was clearly "manmade". We believe that the root causes were the organizational and regulatory systems that supported faulty rationales for decisions and actions, rather than issues relating to the competency of any specific individual' (NAIIC, 2012, p. 16).

All of these accounts of the Fukushima disaster are not only about the disaster itself: They also tell us much about how science and technology is shaped within and sometimes limited by 
the society and culture at large, carrying profound ramifications with respect to scientific literacy as a goal of science education. The 'fail-safe' image of modern science created and perpetuated by science curricula and textbooks must be revised in the light of what we have learnt from the analyses of disasters.

\subsection{Science-related disaster literacy}

Disaster education, sometimes referred to as disaster risk reduction education, is a field primarily concerned with preparing individuals and societies for disasters (Preston, 2012; Shaw, Shiwaku, \& Takeuchi, 2011). In The Hyogo Framework for Action 2005-2015: Building the Resilience of Nations and Communities to Disasters, the importance of education in reducing disaster risks is stressed in terms of its contribution to 'the collection, compilation and dissemination of relevant knowledge and information on hazards, vulnerabilities and capacities' (UNISDR, 2007, p. 8). Although disaster education is an inherently interdisciplinary field that stretches across sociology of disasters, public health, political communications and so on (Preston, 2012), how it relates to the diverse aims of school science has not been discussed much. In the disaster education literature, disaster literacy is defined as 'an individual's ability to read, understand, and use information to make informed decisions and follow instructions in the context of mitigating, preparing, responding, and recovering from a disaster' (Brown, Haun \& Peterson, 2014, p. 267). Narrowing down to its aspects relevant to science, a working definition of science-related disaster literacy would be 'understanding the scientific knowledge related to disasters to utilise it in responding to disaster events on a personal level, and engaging in the social debate on disasters based on scientific understanding'. Here I focus on two of the aims of disaster education that are particularly relevant to science and technology to unpack their implications.

The first component of science-related disaster literacy relates to the personal level of disaster preparedness and response, meaning that understanding the scientific principles that underlie natural and technological disasters actually contributes to the survival and well-being of individuals.. The most famous example that shows the role of scientific knowledge in disaster response is perhaps the story of Tilly Smith, who saved hundreds of people's lives when a tsunami generated from the 2004 Indian Ocean Earthquake hit Maikhao Beach in Thailand. Smith, only ten years old then, quickly recalled what she learnt in a geography lesson two weeks prior. Walking along the beach, she noticed the indications of water leaving the shoreline and suspicious bubbles on the ocean surface and realised that these are the signs of tsunami. Smith told her parents to leave the beach immediately, and they in turn warned other people nearby, preventing serious outcomes for those people (UNDRR, 2005). Another reported case that shows the contribution of science in disaster preparedness involves an eighteen-year-old busboy, Walter Bailey, at the 
Beverly Hills Supper Club fire in Southgate, Kentucky, in 1977. When he saw smoke curling out from the crack of the door, he noticed that it was puffing out in little bursts and thought

'That indicated there was pressure behind the doors', he says, then adding, by way of explanation, 'Science was one of my favourite subjects in high school'. As he watched, the smoke started leaking out through the centre of the doors as well. He wisely decided not to open the doors. (Ripley, 2008, p. 130)

Bailey decided to bypass his reluctant superiors, grabbed the microphone and shouted at people to leave the room immediately, saving hundreds of people's lives. Smith's and Bailey's stories shed light on the fact that 'textbook science' sometimes directly leads to the knowledge necessary for responding to disasters, implying that educators should be aware of such potential contributions of science to disaster preparedness and seek ways to exploit them.

The second element of science-related disaster literacy, while tightly linked to the previous one, focuses on the social role of scientific knowledge and competencies in the public sphere. People are frequently faced with a cacophony of expert opinions on the causes and effects of calamities, and this often challenges the public's trust in science (Mayer, Bergstrand \& Running, 2014). For instance, the government may announce that the radiation level is safe enough, while the media says it is harmful. How are we supposed to act in such a circumstance? As disasters become highly intertwined with science, society and politics, knowledge from diverse domains is required to understand and properly respond to the information about disasters. Because of this, Fortun and Morgan (2015) argued that disaster educators should prioritise 'explanatory pluralism', meaning that people should have a capacity to deal with different types and sources of knowledge when understanding complex phenomena such as disasters. Gunderson and Dietz (2019) also pointed out that scientifically informed deliberation processes are essential for issues involving high degrees of complexity and uncertainty, such as technological disasters.

These two elements of disaster literacy that are required for citizens give important clues to the role of science education in improving disaster preparedness. This draws on the fact that public communication of disaster-related scientific information and making scientifically grounded arguments and informed decisions are core interests of both science education (e.g., Erduran \& Jiménez-Aleixandre, 2007) and STS (e.g., Jasanoff, 1994). Disaster educators should benefit from the theoretical and empirical research that science education researchers have accumulated over decades, and science educators should extend their interest to the various disasters in their own society and beyond.

\section{Towards cross-disciplinary integrations}


How can we translate the foregoing ideas into curriculum and classroom practice? What are the feasible ways in which disaster education and science education can cross-fertilise to deal with post-disaster hardships and prepare citizens for future disasters? A good starting point is to examine this task in terms of the different modes of cross-disciplinary collaboration. According to Klein (2017), multidisciplinarity refers to the juxtaposition or sequencing of several disciplinary approaches to a shared topic, while each discipline retains its identity. Interdisciplinarity, on the other hand, includes various interactions that range from 'simple communication of ideas to the mutual integration of organising concepts, methodology, procedures, epistemology, terminology, data, and organisation of research and education' (OECD, 1972, p. 25). More recently, the concept of transdisciplinary integration has been put forward. This mode features the transcendence and transgression of disciplinary worldviews and the pursuit of overarching, synthetic frameworks across subjects (Klein, 2017).

In light of such a distinction, a realistic point to begin the curricular integration of science and disaster education is multidisciplinary integration. This means both including disaster topics in the science curriculum and highlighting scientific aspects in other subjects where disaster is concerned, collaboratively fostering a deeper understanding of disaster, science and their interrelationship. Moving forward to the next step, an interdisciplinarity can be pursued by engaging students in the relevant topics from an integrated perspective. Cross-curricular collaborations between curriculum makers and between teachers should be encouraged to select the disaster issues, identify the underlying socio-technical actors and networks, and transform these ideas into teaching materials. Hybrids of disaster studies and science such as forensic science, disaster mitigation technology and STS could provide fruitful resources for implementing this mode of teaching. Most of my examples above are focused on this level of integration, in the sense that I focused on the contributions to the existing aims of each discipline (i.e., disaster education and science education). The final level of integration would be seeking a transdisciplinary approach to disaster and science education. Transdisciplinarity in the context of disaster education would involve developing a comprehensive account of disaster and science by utilising STS as a vehicle. It should be noted that these different modes of integration are not mutually exclusive but should be pursued simultaneously by science and disaster educators. The pursuit of such integration will eventually help us take down the border between the two cultures.

In this paper, my aim was to propose a novel perspective on the place of science in the wider discourse on the teaching of disaster. With recent examples, I have illustrated that there are diverse disaster-related issues arising from the mutually independent nature of science and disaster, which has previously been unattended despite their pedagogical significance. The examples that I discussed are not meant to be complete, but I hope that my discussion has delineated the importance of the problem, some key agendas and possible modes of integration well enough to inform the next steps. Turning these 'possibilities' into realities would require long-term efforts 
by means of curriculum reform and teacher education. Now I wish to conclude by addressing several key tasks and challenges that need further considerations and actions. First, to encourage conversation between science and disasters in schools, it is crucial for the curriculum makers to allow teachers more opportunities to initiate and sustain such cross-disciplinary exchanges. Recent curricular emphasis on SSIs around the world (e.g., Ministry of Education of Korea, 2015; National Research Council, 2012; NGSS Lead States, 2013), for example, provides such an arena where integrated approaches to disaster can be discussed and implemented. In most countries where disaster education is not part of the formal curriculum, relevant subjects such as history, social studies, moral education and religious education should be carefully organised to promote students' holistic understanding of disasters that encompasses their human, social and scientific aspects.

Second, more effort is needed to support and prepare teachers for addressing disasters in classrooms, especially given that disasters are often a controversial and sensitive issue that involves a high degree of uncertainty (We frequently see even experts disagreeing about the causes and impacts of a disaster). These controversies not only rage during an outbreak of disasters but also may continue for years or decades in the aftermath of the disaster. Many teachers feel underprepared when teaching controversial issues in their classrooms and often avoid them (Kello, 2016), which is particularly so for science teachers due to the nature of the subject. This indicates that supporting teachers to develop the ability to deal with diverse opinions, facilitate discussion and disclose their own views while avoiding the danger of indoctrination becomes a crucial task (Hand \& Levinson, 2013; Park \& Song, 2019) when disasters are viewed and taught as sociotechnical phenomena. Furthermore, it should be noted that considering tragic events such as a disaster as an object of scientific inquiry bears the risk of objectifying and instrumentalising them in an insensitive manner ${ }^{3}$. Without sufficient care, addressing recent disasters may invoke distress or trauma to some students who were directly or indirectly involved in them. These considerations indicate that teaching disasters from an integrated perspective is not without challenges, which should be carefully sorted out by researchers, curriculum makers, teacher

\footnotetext{
${ }^{3}$ A story of my colleague's may help illustrate this concern more concretely. A few years ago, when she was teaching at a high school in Korea, a group of her students started a plan to take part in a local science competition with a project scientifically investigating the Sewol Ferry disaster that killed over 300 people, mostly students and teachers on their way to the school field trip. The school's head of science stood against this idea on the grounds that it is wrong to exploit other people's tragedy for a personal interest, which made the students withdraw the project and change to another. Although I do not agree that this logic of 'exploitation' should prevent us from addressing disasters in relation to science (for it could be throwing the baby out with the bathwater), this story reminds us that teaching disasters always involve ethical considerations and that teaching them from a scientific standpoint makes no exception to the rule. I thank an anonymous reviewer for directing my attention to this issue of objectification and instrumentalisation which reminded me of the story.
} 
educators and frontline teachers of various subjects. Yet these challenges would not diminish the value of the approach in overcoming the hardship of disasters and fostering responsible and resilient citizens with informed knowledge of science as well as how it operates in society.

\section{References}

American Association for the Advancement of Science. (AAAS) (1989). Science for all Americans. Oxford: Oxford University Press.

Bencze, J. L., \& Alsop, S. (2014) (Eds.). Activist science and technology education. Dordrecht: Springer. Brown, L. M., Haun, J. N., \& Peterson, L. (2014). A proposed disaster literacy model. Disaster Medicine and Public Health Preparedness, 8(3), 267-275.

Cockelbergh, M. (2016). Vulnerability to natural hazards: Philosophical reflections on the social and cultural dimensions of natural disaster risk. In P. Gardoni, C. Murphy, \& A. Rowell (Eds.), Risk analysis of natural hazards: Interdisciplinary challenges and integrated solutions (pp. 27-41). Heidelberg: Springer.

Dowty, R. A., \& Allen, B. L. (2011). Introduction. In R. A. Dowty \& B. L. Allen (Eds.), Dynamics of disaster: Lessons on risk, response and recovery (pp. 1-10). London: Earthscan.

Dusek, V. (2006). Philosophy of technology: An introduction. Malden, MA: Blackwell.

Dynes, R. (2000). The Lisbon earthquake in 1755: Contested meanings in the first modern disaster. TsuInfo Alert, 2, 10-18.

Erduran, S., \& Jiménez-Aleixandre, M. P. (2007). Argumentation in science education: Perspectives from classroom-based research. Dordrecht: Springer.

Evan, W. M., \& Manion, M. (2002). Minding the machines: Preventing technological disasters. Upper Saddle River, NJ: Prentice Hall.

Fien J. 1993, Education for the environment: Critical curriculum theorising and environmental education. Victoria: Deakin University Press.

Fischer, M. M. J. (2019). The pedagogical work of film for technology disaster studies: Reassessing Fukushima through film. East Asian Science, Technology and Society, 13(2), 345-354.

Fortun, K., \& Frickel, S. (2013). Making a case for disaster science and technology studies.

Retrieved from An STS Forum on the East Japan Disaster at https://fukushimaforum.wordpress.com/online-forum-2/online-forum/making-a-casefor-disaster-science-and-technology-studies/

Fortun, K., \& Morgan, A. (2015). Thinking across disaster. In J. Shigemura \& R. K. Chhem (Eds.), Mental health and social issues following a nuclear accident: The case of Fukushima (pp. 55-64). Dordrecht: Springer.

Fortun, K., Knowles, S. G., Choi, V., Jobin, P., Matsumoto, M., Torre, P. de la, et al. (2016). Researching disaster from an STS perspective. In U. Felt, R. Fouché, C. A. Miller, \& L. Smith- 
Doerr (Eds.), Handbook of science and technology studies (4th ed., pp. 1003-1028). Massachusetts, MA: MIT Press.

Frassen, M., Lokhorst, G.-J., \& van de Poel, I. (2018). Philosophy of technology. In E. N. Zalta (Ed.), Stanford encyclopedia of philosophy (Fall 2018 Edition). Available online at https://plato.stanford.edu/archives/fall2018/entries/technology/

Fujigaki, Y. (2015). The process through which nuclear power plants are embedded in political, economic, and social contexts in Japan. In Y. Fujigaki (Ed.), Lessons from Fukushima: Japanese studies on science, technology and society (pp. 7-26). Dordrecht: Springer.

Funtowicz, S. \& Ravetz, J. (1993). Science for the post-normal age, Futures, 31(7), 735-755.

Giddons, A. (1995). Beyond left and right. Cambridge, MA: Polity.

Grigoli, F., Cesca, S., Rinaldi, A. P., Manconi, A., López-Comino, J. A., Clinton, J. F., et al. (2018). The November 2017 Mw 5.5 Pohang earthquake: A possible case of induced seismicity in South Korea. Science, 360(6392), 1003-1006.

Gunderson, R., \& Dietz, T. (2019). Deliberation and Catastrophic Risks, In A. Bächtiger, J. S. Dryzek, J. Mansbridge, \& M. Warren (Eds.), The Oxford handbook of deliberative democracy. Retrieved 24 June 2019 from https://doi.org/10.1093/oxfordhb/9780198747369.013.18

Hand, M., \& Levinson, R. (2012). Discussing controversial issues in the classroom. Educational Philosophy and Theory, 44(6), 614-629.

Hara, T. (2013). Social shaping of nuclear safety: Before and after the disaster. In R. Hindmarsh (Ed.), Nuclear disaster at Fukushima Daiichi: Social, political and environmental issues (pp. 22-40). London: Routledge.

Hewitt, K. (1997). Regions of risk: A geographical introduction to disasters. Essex: Addison Wesley Longman.

Hindmarsh, R. (2013) (Ed.). Nuclear disaster at Fukushima Daiichi: Social, political and environmental issues. London: Routledge.

Irwin, R. (2019). Heidegger and Stiegler on failure and technology. Educational Philosophy and Theory. Advance online publication. doi:10.1080/00131857.2019.1654855

Israel, J. I. (2011). Nature and providence: Earthquakes and the human condition. In Democratic enlightenment: Philosophy, revolution, and human rights, 1750-1790. Oxford: Oxford University Press.

Jasanoff, S. (1994). Learning from disaster: Risk management after Bhopal. Philadelphia, PA: University of Pennsylvania Press.

Johnson, V. A., Ronan, K. R., Johnston, D. M., \& Peace, R. (2014). Evaluations of disaster education programs for children: A methodological review. International Journal of Disaster Risk Reduction, 9, 107-123.

Kello, K. (2016). Sensitive and controversial issues in the classroom: Teaching history in a divided society. Teachers and Teaching, 22(1), 35-53. 
Klein, J. T. (2017). Typologies of interdisciplinarity: The boundary work of definition. In R. Frodeman (Ed.), The Oxford handbook of interdisciplinarity (2nd ed., pp. 21-34). Oxford: Oxford University Press.

Kim, Y., \& Sohn, H.-G. (2018). Disaster Risk Management in the Republic of Korea. Springer Singapore. Knowles, S. G. (2014). Engineering risk and disaster: A special issue of Engineering Studies. Engineering Studies, 6(3), 131-133.

Kroes, P., \& Meijers, A. (Eds.) (2001). The empirical turn in the philosophy of technology. Amsterdam: Elsevier Science.

Latour, B. (1987). Science in action: How to follow scientists and engineers through society. Cambridge, MA: Harvard University Press.

Latour, B. (1999). Pandora's hope: Essays on the reality of science studies. Cambridge, MA: Harvard University Press.

Lauta, K. C. (2018). Disasters and responsibility: Normative issues for law following disasters. In D. O’Mathúna, V. Dranseika, \& B. Gordijn (Eds.). Disasters: Core concepts and ethical theories (pp. 43-54). Dordrecht: Springer.

Law, J. (1991). Introduction: Monsters, machines and socio-technical relations. In J. Law (Ed.), A sociology of monsters? Essays on power, technology and domination (pp. 1-23). London: Routledge.

Lee, Y. C. (2008). Exploring the Roles and Nature of Science: A case study of severe acute respiratory syndrome. International Journal of Science Education, 30(4), 515-541.

Lee, Y., \& Jeon, C. (2015). Teaching Sewol Disaster. https://www.4sonline.org/md/post/teaching_sewol_disaster

Leibniz, G. W. (1985). Theodicy: Essays on the Goodness of God, the freedom on man and the origin of evil (E. M. Huggard, Trans.). La Salle, IL: Open Court. Original work published in 1710.

Lung Injury Investigation Committee (LIIC). (2014). White paper on the health damage disaster from humidifier disinfectants. Sejong: Korean Ministry of Health and Welfare.

Mayer, B., Bergstrand, K., \& Running, K. (2014). Science as comfort: The strategic use of science in post-disaster settings. In D. L. Kleinman \& K. Moore (Eds.), The Routledge handbook of science, technology, and society (pp. 419-433). New York, NY: Routledge.

Ministry of Education of Korea. (2015). National curriculum: Science. Sejong: Ministry of Education of Korea.

Molesky, M. (2015). This gulf of fire: the destruction of Lisbon, or apocalypse in the age of science and reason. New York, NY: Alfred A. Knopf

National Research Council. (2012). A framework for K-12 science education: Practices, crosscutting concepts, and core ideas. Washington, DC: National Academies Press.

NGSS Lead States. (2013). Next generation science standards: For States, by States. Washington, DC: National Academy Press. 
National Diet of Japan Fukushima Nuclear Accident Independent Investigation Commission (NAIIC). (2012). The official report of The Fukushima Nuclear Accident Independent Investigation Commission. Tokyo: The National Diet of Japan.

Nielson, S., \& Lidstone, J. (1998). Public education and disaster management: Is there any guiding theory? Australian Journal of Emergency Management, 14-19.

Onaga, L. (2011). Teach 3.11: Participatory educational project puts the kanto-tohoku disaster into historical context. East Asian Science, Technology and Society, 5(3), 417-422.

Organization for Economic Cooperation and Development. (OECD) (1972). Interdisciplinarity: Problems of teaching and research in universities. Paris: OECD.

Park, W., \& Song, J. (2019). Between realism and constructivism: A sketch of pluralism for science education. In E. Herring, K. Jones, K. Kiprijanov, \& L. Sellers (Eds.), The past, present and future of integrated history and philosophy of science (pp. 228-247). London: Routledge.

Perrow, C. (1983). The organizational context of human factors engineering. Administrative Science Quarterly, 28(4), 521-541.

Perrow, C. (1999). Normal accidents: Living with high risk technologies. Princeton, NJ: Princeton University Press.

Peters, M. A., Rider, S., Hyvönen, M., \& Besley, T. (2018) (Eds.). Post-truth, fake news: Viral modernity \& higher education. Dordrecht: Springer.

Pinch, T. J. (2012). How do we treat technical uncertainty in systems failure? The case of the Space Shuttle Challenger. In T. R. La Porte (Ed.), Social responses to large technical systems: Control or anticipation (pp. 143-158). Dordrecht: Springer.

Preston, J. (2012). Disaster education: 'Race', equity and pedagogy. Rotterdam: Sense Publishers.

Qualifications and Curriculum Authority. (2005). Science: Changes to the curriculum from 2006 for Key Stage 4 [Electronic Version]. Retrieved 28 December 2019 from https://www.stem.org.uk/resources/elibrary/resource/29137/science-changes-

curriculum-2006-key-stage-four

Ripley, A. (2008). The unthinkable: Who survives when disaster strikes -- and why. New York, NY: Crown.

Sadler, T. D., \& Zeidler, D. L. (2003). Scientific errors, atrocities, and blunders. In D. L. Zeidler (Ed.), The role of moral reasoning on socioscientific issues and discourse in science education (pp. 261-287). Dordrecht: Kluwer.

Shaw, R., Shiwaku, K., \& Takeuchi, Y. (2011). Disaster education. Bingley: Emerald.

Snow, C. P. (1959). The two cultures and the scientific revolution. Oxford: Oxford University Press.

United Nations International Strategy for Disaster Reduction (UNISDR). (2007). Hyogo Framework for Action 2005-2015: Building the Resilience of Nations and Communities to Disasters. $\quad$ Retrieved from https://www.unisdr.org/files/1037_hyogoframeworkforactionenglish.pdf (Accessed 27 June 2019) 
United Nations Office for Disaster Risk Reduction (UNDRR). (2005, November 3). British schoolgirl hero meets President Clinton 'All children should know what a tsunami is ... and how to react', says Tilly Smith. UNDRR News Archive. Retrieved from https://www.unisdr.org/archive/5635 (Accessed 27 June 2019)

Vesterinen, V.-M., Manassero-Mas, M.-A., \& Vázquez-Alonso, Á. (2014). History, philosophy, and sociology of science and science-technology-society traditions in science education: Continuities and discontinuities. In M. R. Matthews (Ed.), International Handbook of research in history, philosophy and science teaching (pp. 1895-1926). Dordrecht: Springer.

Wong, S. L., Kwan, J., Hodson, D., \& Yung, B. H. W. (2009). Turning crisis into opportunity: Nature of science and scientific inquiry as illustrated in the scientific research on severe acute respiratory syndrome. Science er Education, 18(1), 95-118.

Zeidler, D. L., Sadler, T. D., Simmons, M. L., \& Howes, E. V. (2005). Beyond STS: A research-based framework for socioscientific issues education. Science Education, 89(3), 357-377. 